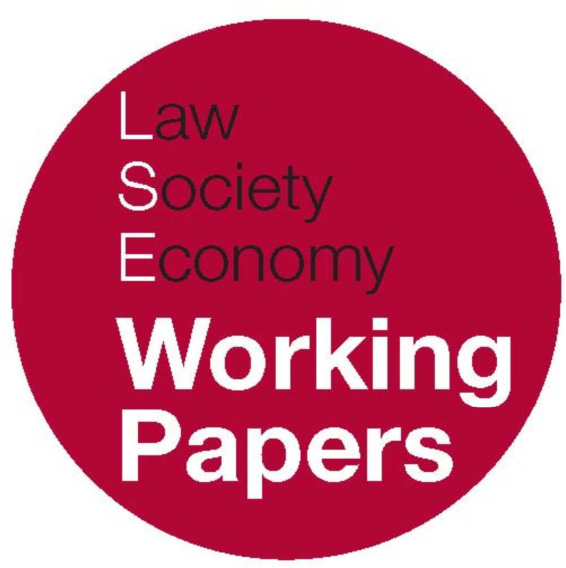

\title{
Fitness to Plead and Core Competencies: Problems and Possibilities
}

\author{
Jill Peay \\ LSE Law, Society and Economy Working Papers 2/2012 \\ London School of Economics and Political Science \\ Law Department
}

\begin{abstract}
This paper can be downloaded without charge from LSE Law, Society and Economy Working Papers at: www.lse.ac.uk/collections/law/wps/wps.htm and the Social Sciences Research Network electronic library at: http://ssrn.com/abstract=1991265.

(C) Jill Peay. Users may download and/or print one copy to facilitate their private study or for non-commercial research. Users may not engage in further distribution of this material or use it for any profit-making activities or any other form of commercial gain.
\end{abstract}




\title{
Fitness to Plead and Core Competencies: Problems and Possibilities
}

\author{
Jill Peay ${ }^{*}$
}

\begin{abstract}
Written in the light of the Law Commission's Consultation Paper on Unfitness to Plead, this paper examines some of the core competencies that should underpin a test of unfitness to plead. It comprises three broad sections: (i) an examination of the current problems with unfitness and the foundational principles for a revised test, (ii) a description of the prevailing test of unfitness and of those that might be used to reformulate it, and (iii) an examination of the core competencies that would be required in an accused person to facilitate proper engagement with a criminal trial. An Appendix details some of the working criteria which emerged during the formulation of the psychiatric test currently under development by the Nuffield Foundation-funded research team.
\end{abstract}

\footnotetext{
* Professor of Law, London School of Economics and Political Science. This working paper was prepared in association with work conducted under the terms of a three-year grant from the Nuffield Foundation 'Fitness to plead: The impact of cognitive abilities and psychopathology' by Nigel Blackwood (Kings College London), Michael Watts (University College London), and Jill Peay (LSE). Rebecca Brewer and Elizabeth Appiah-Kusi were employed on the research team, and a number of others were involved in a voluntary capacity in the development of the unfitness to plead instrument, most notably Dexter Dias, Edward Henry, Tim Rogers, Anna Morris, Terence Woods, and a number of High Court Judges. The project also built on earlier work by Tim Rogers, Nigel Blackwood, Frank Farnham, Graham Pickup, and Mike Watts (see nn 109 and 111 below). Edward Henry played a key role in the development of the Appendix on Core Competencies. I am grateful to all of these individuals, but am responsible for what appears here.
} 


\section{INTRODUCTION}

It does not require the matters with which it deals to be resolved with mathematical accuracy. The essential question is whether the alleged inequality of arms is such as to deprive the accused of his right to a fair trial.

Lord Hope of Craighead ${ }^{1}$

This paper addresses some of the problems and possibilities concerning the fairness of our current arrangements around fitness to plead. Fitness to plead refers to those procedures which determine whether or not an accused person should be subject to a criminal trial when their ability to enter a plea (and thereafter, if necessary, take part in a trial) is compromised because they are not of 'sound mind'.2 Subjecting such individuals to plea and trial entails two risks. First, of wrongful convictions, in that an accused may not have committed the offence, and yet he or she cannot properly defend him or herself. And second, of undermining confidence in the law: if the law is seen to impose its full rigour on those who cannot fairly participate in their own trials, albeit they may have committed the offence charged, public support for the law will be jeopardised.

Paradoxically, there are equally strong arguments in favour of ensuring that all those who can properly be tried, should be so tried. To deny those whose capacities are limited in some way from the benefits of timely trials is potentially discriminatory; if, with the requisite support, a trial can proceed fairly it should. ${ }^{3}$ Thus, the problem in this field is one of correctly separating those who should and should not be subject to plea and trial, and doing so on an agreed and fair basis.

This paper, written in the light of the Law Commission's Consultation Paper on Unfitness, ${ }^{4}$ but before delivery of their final report ${ }^{5}$ is designed to examine some of the core competencies that should underpin a test of unfitness to plead. It comprises three broad sections: (i) an examination of the current problems with unfitness and the foundational principles for a revised test, (ii) a description of the prevailing test of unfitness and of those that might be used to reformulate it, and (iii) an examination of the core competencies that would be required in an accused person to facilitate proper engagement with a criminal trial. There is then an Appendix which represents some of the working criteria which emerged during the formulation of the psychiatric test currently under development.

\footnotetext{
${ }^{1}$ Referring to the purpose of Article 6 of the European Convention on Human Rights (ECHR) in the Privy Council case of McLean \& Anor v Procurator Fiscal (Scotland) [2001] UKPC D3 at [39].

${ }^{2}$ Lord Bingham R v Antoine [2001] 1 AC 340, 344.

${ }^{3} \mathrm{R}(\mathrm{C})$ v Sevenoaks Youth Court [2009] EWHC 3088.

${ }^{4}$ Law Commission, 'Unfitness to Plead' (Consultation Paper no. 197, 2010).

5 This is likely to be delayed because of the Law Commission's parallel consultation in 2012 on 'Insanity' (relating to the special verdict of not guilty by reason of insanity under the M'Naghten Rules).
} 
Whilst the paper concludes that fairness should be the key underpinning legal concept, it argues that in order to achieve legal fairness the accused must be able to play a proper part in the adjudicative process. Central to this is the notion that a range of core competencies should be present in the accused or, where these may be deficient, that there is an opportunity to supplement them through appropriate support or other guidance. In the absence of either core competencies or appropriate support, accused persons should be subject to the unfit to plead provisions.

\section{PROBLEMS WITH PROCEDURE}

Determining that someone is unfit to plead entails a potentially awkward interaction between medical and legal professionals and between their intersecting values. Not only is the determination of 'unfitness' made by the judge on the basis of advice from mental health professionals (advice which the judge may reject), but the process and disposal options which follow are also contentious. Where unfitness is found a hearing will take place - known as the trial of the facts which determines whether the accused 'did the act or made the omission charged'. ${ }^{6}$ This trial of the facts does not constitute criminal proceedings: 7 indeed, the responsibility placed on a person appointed by the court to represent an unfit person during the trial of the facts is 'quite different from the responsibility placed on an advocate where he or she could take instructions from a client'; 8 and the best person to do this may not be the person who had represented the accused during the determination of unfitness. ${ }^{9}$

All of this would imply that a criminal trial, and the plea which is necessarily a part of it, is categorically different from the trial of the facts: a position (controversially) adopted by the House of Lords in $\mathrm{R} v \mathrm{H}$ in its consideration of Article 6 of the ECHR. ${ }^{10}$ Indeed the Law Commission, in analysing the implications of the judgment (to the effect that accused persons enjoy lesser protections during the trial of the facts than those to which they might otherwise be entitled were these proceedings regarded as essentially criminal in nature and thus eligible for the full protection of Article 6), drew attention to some of the anomalies that lay behind the House of Lords' narrow approach to the issues in $R$ $\mathrm{v} H .{ }^{11}$ In particular, their failure to acknowledge that hospital orders are criminal disposals imposed primarily following a criminal conviction. The Law Commission noted the importance of looking at the substance of disposals and

\footnotetext{
${ }^{6}$ Criminal Procedure (Insanity) Act 1964, s 4A(2)(b).

7 R v H and Secretary of State for the Home Department [2003] UKHL 1.

${ }^{8} \mathrm{R} v \mathrm{~N}$ Norman Court of Appeal, The Times 21 August 2008.

9 Notably, the advocate for the unfitness determination is remunerated by the Criminal Defence Service, and that for the trial of the facts out of central funds.

10 n 7 above.

11 n 4 above, ss 6.47-6.48.
} 
not just at their appearance as non-punitive: and they supported the view that, in their current form, section 4A hearings had a hybrid nature, being simultaneously both civil and criminal.

Integral to this is also the notion that the disposal options are contentious. Whilst the judge can direct either an absolute discharge or a supervision order in the community for two years, the third disposal option is admission to a psychiatric hospital under the equivalent of a hospital order with (or without) restrictions attached. And this is the one provision where a court can order a psychiatric hospital to accept the admission of a person found 'unfit' even though clinicians may not be recommending admission. In all other circumstances clinicians have the final say over which individuals are admitted as patients.

Something of the nature of these dilemmas has been captured in the Court of Appeal in the recent case of $\mathrm{R} v \mathrm{~W}$ alls, ${ }^{12}$ which post-dated publication of the Law Commission's Consultation Paper. Walls had been tried and convicted of offences of sexual assault on a child under 13 and sentenced to a community order with a three-year supervision requirement and a requirement that he attend and complete the 'Adapted Sex Offender Treatment Programme'. The appeal concerned whether fresh evidence of his low IQ (of between 63-71 - in the extremely low-to-borderline range of intelligence) should be admitted to establish that he had been unfit to plead at his original trial within the Pritchard criteria, as interpreted in the case of Podola ${ }^{13}$ (the 1836 case of Pritchard being the leading case on unfitness). ${ }^{14}$ In short the issue was whether his low IQ and learning disability affected his ability to participate in a criminal trial. At the appeal two psychiatrists gave evidence asserting that Robert Walls would not have been fit to plead, but did not make reference to the Pritchard criteria in their formal reports. The Court of Appeal made clear that the duty of the court was to consider whether the defendant was unfit to plead according to those criteria in the light of all the evidence before it, including the expert psychiatric evidence. Manifestly, the clinical evidence was not to be the final word on the matter.

Whilst the Court of Appeal rejected the evidence of one of the psychiatrists as evidence on which it did not feel it could rely, the evidence of the other psychiatrist was considered in the light of the Pritchard criteria, the police interviews with the appellant, evidence concerning the trial, and the actions (and inactions) of various parties (solicitor, appropriate adult, CPS, the trial judge, and the advocate for the Crown). At the time, no one had suggested Walls was unfit, or that any intermediary ought to be appointed by the court under its powers. ${ }^{15}$ In a context where the Court of Appeal was also mindful of the serious nature of depriving an accused of the significant rights that accrue in a trial (as opposed to the 'trial of the facts' procedure), was aware of the half-way house of providing in-

12 R v Walls [2011] EWCA Crim 443.

13 Podola (1960) 1 QB 325.

14 Pritchard (1836) 7 C \& P 303.

15 See $\mathrm{n} 3$ above. 
court assistance to those with learning disability, and was anxious about the limited disposal options following a positive finding if the unfit route were adopted limited in the sense of their ability to protect the public or assist the defendant - it is perhaps not surprising that they rejected the appeal. Although there would be cases where, on the evidence, unfitness was clear, even where psychiatrists agreed that a defendant was unfit, 'a court would be failing in its duty to both the public and a defendant if it did not rigorously examine the evidence and reach its own conclusion'. ${ }^{16}$ In rejecting the appeal it is notable that the Court of Appeal observed that the three-year community order to which the original court had sentenced Walls was a year longer than that which he could have been given under the unfitness route. This was regarded as beneficial to Walls and as protective of the public. Indeed they argued that had the unfitness route been adopted, the choice either between a hospital order and a two-year supervision order would have been less satisfactory than the outcome achieved through the sentencing process.

\section{A PRINCIPLED APPROACH?}

So why might clinicians and lawyers find themselves at odds? Since both law and medicine embrace multiple philosophies, with neither having one agreed defining objective, thinking about the relationship between them will throw up some areas where the ground between them is shared, and others where it is more problematic. Fitness to plead arguably falls into the latter category.

It is commonly held that one core concept for medical practitioners is primum non nocere: first, do no harm. This is partially embodied in the Hippocratic Oath's exhortation to 'never do harm'; or in another translation, to keep the sick from 'harm and injustice'. The extent to which doctors would be better doing nothing rather than risking causing harm is however debatable, since it is well recognised that in some circumstances primum succurrere - first, hasten to help - may be more appropriate (and more intuitively welcome to those who define themselves as in need). Indeed, the positive duty to 'prescribe regimens for the good of my patients' in the Hippocratic Oath precedes the notion of 'doing no harm'. Yet doctors' training and special expertise places them not only under an ethical duty to enhance the welfare of their patients (beneficence), but also to avoid doing harm by treating a patient negligently. 'Negligent' treatment may come about either through doing too much - overtreatment - which results in harm; or from doing too little, a form of therapeutic nihilism. Inevitably, achieving the balance between beneficence and non-maleficence lies at the heart of medical intervention, since most such interventions entail some degree of risk or harm before good can be brought about; the key question is whether the harm done or risked is proportionate to the benefit anticipated.

\footnotetext{
${ }^{16} \mathrm{n} 12$ above, at [38].
} 
This bipartite approach, of blending the avoidance of harm whilst simultaneously doing good, does resonate with the law's aspirations on unfitness to plead, albeit that the law's approach is a more unhappy choice between two potentially competing alternatives of what 'fairness' means. Thus, is the law interested primarily in treating people fairly, a positive duty and arguably a broad one? As Duff puts it, 'a defendant should be held unfit to plead if, and only if, his condition is such that it precludes a fair trial'; $; 1$ and a fair trial is one that entails meaningful participation by the accused. Or is the focus on fairness one more procedurally based, that is in ensuring that the conviction of innocent people, or of unsafe verdicts, is avoided; in essence, is the verdict, in Grubin's terms, reliable?18 This latter approach, a procedural justice approach to fairness, embodies what lawyers do not want to happen. Or in William Blackstone's 1760s formulation, it is 'better that ten guilty persons escape than that one innocent suffer'. ${ }^{19}$ The numbers in this balancing act with respect to conviction have varied over time, depending on whether a defendant or victim perspective is favoured, but the equation rests on notions of the potential unreliability of verdicts.

Transposed to 'unfitness to plead' the equation becomes more opaque. Being found unfit to plead does not constitute a straightforward choice between conviction or acquittal (or unjust conviction and unjust acquittal), because those for whom a positive finding of 'unfitness' is made, will then be subject to the 'trial of the facts'. These proceedings, essentially civil in nature, ${ }^{20}$ determine whether the accused 'did the act or made the omission charged' and do not necessitate that the accused participate in any particular fashion, or even necessarily be present for the proceedings. A positive jury finding leads to the disposal options mentioned above. A negative finding means that the accused 'walks free', albeit that identification of a highly problematic mental state may render him or her liable to civil admission to a psychiatric hospital.

Is unfitness to plead founded then on achieving positive fairness or avoiding procedural injustice? Although the latter has historically been conceptualised as the primary rationale for unfitness, ${ }^{21}$ this paper argues in favour of the former, in essence following Duffs (1994) argument that fitness to plead, and any trial that ensues, is a communicative process in which the accused answers any prosecution case made out and is open to the censuring process that may follow conviction. The convicted accused is, in Duff's words 'a rational and responsible agent'22 who will be held to account having engaged with the court as an active participant in

${ }^{17}$ R. A. Duff, 'Fitness to Plead and Fair Trials: Part 1: A Challenge' (1994) Crim LR 419, 419.

${ }^{18}$ D. Grubin, 'Fitness to Plead and Fair Trials: Part 2: A Reply' (1994) Crim LR 423.

${ }^{19}$ W. Blackstone Commentaries on the Laws of England (Oxford: Clarendon Press, 1765-1769).

${ }^{20} \mathrm{~J}$. Peay, 'Civil Admission Following a Finding of Unfitness to Plead' in B. McSherry and P. Weller (eds), Rethinking Rights-Based Mental Health Laws (Oxford: Hart Publishing, 2010).

${ }^{21}$ In short, avoiding wrongful convictions and the threat to the integrity of the trial process were uncomprehending defendants to be tried.

22 n 17 above, 420 . 
their own trial. If the accused is unable to participate, then he or she cannot be tried fairly.

Quite how far down the Duff route one might want to go is seen by some as problematic. $^{23}$ Understanding the normative dimensions of a trial, as opposed to ensuring pragmatic effective engagement with that process through proper communication, might be seen as going beyond what even the ECtHR has required. ${ }^{24}$ However, since conventional trials are followed by punishment, or a combination of punishment and rehabilitative efforts, engaging effectively in that process does entail an ability to recognise the moral (or immoral) dimensions of what one has done. Those who have the capacity to understand these normative aspects, but reject them, are proper subjects for trial. Those who cannot, may not be; and to punish those who cannot understand its rationale should make all of us deeply uncomfortable.

One other argument is relevant to this broader approach to fairness. Whilst unfitness to plead was originally a temporary procedural provision, it has transformed into, for the most part, a substantive outcome. ${ }^{25}$ And the substantive outcome following a finding of unfitness and a determination that the individual did the act or made the omission charged is a disposal option that does not require the 'effective participation' of the unfit person. These disposal options are limited to compulsory admission to hospital, supervision and treatment orders (where the accused is required to submit to medical treatment - the only explicit mention of requiring the patient's consent is where the supervisor wishes to give treatment at a place or institution not specified in the order ${ }^{26}$ ), or an absolute discharge. They arguably and contrastingly do not require the normative understanding entailed for convicted defendants in what it means to be censured by conventional punishment.

\section{THE CONCEPT OF EFFECTIVE PARTICIPATION}

In arguing for a broader approach based on fairness this paper draws heavily on the work of the Scottish Law Commission ('SLC') 27 on its earlier Discussion Paper in 2003,28 and on the case from Jersey of Attorney General v O'Driscoll:29 all of these

\footnotetext{
23 For example, see Law Reform Committee of the Bar Council and the Criminal Bar Association of England and Wales, 'Unfitness to Plead. A Response to the Law Commission CP 197' (25 January 2011), 67.

24 See T v UK; V v UK (2000) 30 EHRR 121; SC v UK (2005) 40 EHRR 10 at 29. See also Law Commission, $\mathrm{n} 4$ above, para 2.102.

${ }^{25}$ Now only those who receive disposals of an admission order with a restriction order attached have a right to be returned to court for a trial should their condition improve (see Sched 1, s 4(2) of the Criminal Procedure (Insanity and Unfitness to Plead) Act 1991, which permitted the Home Secretary to remit for trial those given admission orders with restrictions, but not those given merely admission orders: the admission order equates to a hospital order under the Mental Health Act 1983, which can be made with or without a restriction order attached).

26 See Sched 2, s 4(4). This would not be to imply that the order overrides the need for consent if medical treatment is given.

27 SLC, Report on Insanity and Diminished Responsibility (SE/2004/92, no, 195, 2004).

28 SLC, Discussion Paper, (no. 122, 2003).
} 
formulate a test of unfitness in terms of effective participation. ${ }^{30}$ The concept of effective participation derives in part from consideration by the European Court of Human Rights (ECtHR) of Article 6 (broadly, the right to a fair trial). Similarly, the British Psychological Society, in its submission to the Bradley review, argued that the accused 'must be capable of contributing to the whole process of his or her trial, starting with entering a plea'..$^{31}$

Thus, the Scottish Law Commission asserted, 'the question of whether an accused is a fit person to be subjected to a criminal trial is not merely a procedural preliminary to a case proceeding but is a substantive precondition to the legitimacy of the whole trial process'. 32

This is important since it takes the consideration of unfitness to plead away from a narrow focus on the accused's response to the indictment to embrace the ability of the accused properly to engage with the trial itself. A number of issues arise from this and are discussed below. Finally, it is important to note that taking this broad view similarly engages the issue of fitness to plead guilty, since it is only fair guilty pleas, ones where the accused has the requisite capacities to understand the normative dimensions of punishment, that could be sustained by a system that strives to achieve effective (ie meaningful) participation by the accused.

But the focus on effective participation leads to its own problems; for example, within the case law there is some confusion as to whether a test of unfitness ought to include those with learning disability. Difficulty in understanding the trial based on poor education or social disadvantage (or difficulty in acting in one's own best interests) ${ }^{33}$ will not constitute a sufficient basis for unfitness. ${ }^{34}$ As the SLC advocate, what is required is some underlying clinically recognised condition, ${ }^{35}$ which has the effect of significantly undermining the accused's capacity for effective participation. The SLC argue that merely being puzzled or perplexed by the process would not be sufficient, although it does acknowledge that the suggestion that the legal advisor can interpret for the accused person is an insufficient response since pleas require an accused to 'fully and meaningfully communicate with his lawyer'. ${ }^{36}$ Similarly, developmental immaturity over the age of 10 would not, in itself, be sufficient to make a trial unfair, where the accused had representation, and proper adjustments were made to the trial to take account of the accused's age; ${ }^{37}$ but a clinical condition in a young defendant, for example post-traumatic stress disorder, might make the trial unfair. One way

${ }^{29}$ Royal Court of Jersey (Samedi Division) (9 July 2003).

30 Attorney General v O'Driscoll [2003] Jersey Law Review 390, had similarly drawn on the work of the SLC's Discussion Paper.

${ }^{31}$ Lord Keith Bradley, Lord Bradley's Review of People with Mental Health Problems or Learning Disabilities in the Criminal Justice System (London: Department of Health, COI, 2009), 60.

32 n 27, s 5.55.

${ }^{33} \mathrm{R}$ v Robertson [1968] 3 All ER 557.

34 See variously O'Driscoll, n 30 above, at [32]; SLC, n 27 above, s 4.16.

35 SLC, ibid.

36 ibid.

$37 T$ and $V$ v UK (2000) 30 EHRR 121. 
of interpreting this is that effective participation can be achieved even for those with various forms of learning disability if appropriate support is given in court. Lord Bradley has recommended: 'Immediate consideration should be given to extending to vulnerable defendants the provisions currently available to vulnerable witnesses'; 38 that is, the special measures under the Youth Justice and Criminal Evidence Act 1999 to reduce the stresses associated with a court appearance so that individuals can give their best evidence. ${ }^{39}$ The measures are regarded as particularly important with regard to communication.

Of course, all of this presupposes that the condition itself will be readily recognised; and even the Bradley Report accepts that identifying those with mental health difficulties, and learning disability in particular, is problematic. Moreover, expert (medical) evidence is required to determine the precise manner in which the underlying condition prevents the accused from engaging with the process; and, if having engaged with the trial process, an accused makes a submission of unfitness during that process, the judge can reject this where only one medical opinion is submitted. ${ }^{40}$ Again, the limited purchase that medical evidence has in this context looks evident.

Yet in practice the situation is somewhat different, at least in respect of learning disability. Medical evidence of mental impairment underpins the empirical findings that mental impairment is one of the key bases for unfitness; indeed mental impairment is the main diagnosis in 21 per cent of cases, ${ }^{41}$ albeit that there are only a very limited number of unfitness findings each year. ${ }^{42}$

\section{A SHORT DIVERSION INTO HISTORY}

Despite this confused status, it is important to recall, as Loughnan carefully documents, that the use of the term "insanity" (and subsequently non compos mentis) was used to cover both 'idiots and lunatics', ${ }^{43}$ in essence everyone of unsound mind. Indeed, as she observes, drawing on the work of Nigel Walker, unfitness to plead started its life as much as a way of dealing with the problems of those who

\footnotetext{
${ }^{38} \mathrm{n} 31$ above, 61.

39 Partially implemented under the Coroners and Justice Act 2009 amendments to the Youth Justice and Criminal Evidence 1999; see Hoyano, who describes the Government's response to Bradley in this regard as 'pusillanimous', since vulnerable adult defendants will have to demonstrate that they are unable to participate effectively, rather than merely having diminished capacity, as applies to child defendants and witnesses: L. Hoyano, 'Coroners and Justice Act 2009: (3) "Special Measures Directions Take Two: Entrenching Unequal Access to Justice"” (2010) Crim LR 345, 358.

${ }^{40}$ Determinations of unfitness to plead require two or more registered medical practitioners, at least one of whom is approved, to give written or oral evidence. Moreover, the Judge is entitled to refuse to discharge the jury where, mid-trial, and the defendant has given evidence and instructions, and the Judge has observed this, when faced with a letter from single psychiatrist saying the accused was unfit. $\mathrm{R} \mathrm{v}$ Ghulam, The Times (CA, 26 October 2009).

${ }^{41}$ D. Grubin, 'Unfit to Plead in England and Wales, 1976-1988 A Survey' (1991) 158 British Journal of Psychiatry 540.

42 See the research by R. Mackay in $\mathrm{n} 4$ above, Appendix C, which indicates there are currently about 100 cases per year where unfitness is established.

${ }^{43}$ A. Loughnan, Mental Incapacity Defences in Criminal Law (PhD thesis, Law Department, LSE, December 2007), 46-47.
} 
could not communicate (the deaf and dumb) as with those who had comprehension difficulties (the mentally ill and intellectually impaired). ${ }^{44}$ Moreover, although the 'deaf and dumb' could be tried if they had sufficient understanding, problems relating to their physical inability to communicate would prevent a trial if no sufficient understanding could be established for them to be tried fairly. In contrast, those who refused to communicate - 'mute by malice' could be confined and starved and, from the fifteenth century, subjected to a form of torture, known as pressing by stone, to make them enter a plea if they had the capacity to communicate. ${ }^{45}$ This procedure, albeit rare, was formally ended in 1772 , when standing mute was to be taken as pleading guilty. Only those who were 'mute by visitation of God' were protected, and they could have a plea of not guilty entered on their behalf, and tried, albeit cautiously, once sufficient understanding was established; where 'madness was real', accused persons would be protected from trial until such time as they were fit. ${ }^{46}$ Thus, arrangements covered both those with physical and mental incapacities, that is, incapacities of either communication and / or comprehension. But facilitating participation was a key objective.

As will be noted below, and as Grubin illustrates, the distinction between those who did not have the capacity to be tried, and those who temporarily were unable to use the capacities they had, became confused in the cases of Dyson 1831 and then Pritchard 1836, both of whom were 'deaf and dumb', albeit that the key issues concerned whether lying beyond their communication difficulties were difficulties of comprehension. ${ }^{47}$ The judgments reflect this focus on cognitive capacities (or their lack of them). But it is true to say that both the nineteenth century madmen and their 'deaf and dumb' counterparts clearly did not have the requisite capacities at the requisite time.

If it is the capacity to participate that is critical, some anomalies remain. Physical disorders that may affect one's ability to participate in a trial can result in arrangements being made to accommodate the effects of those disorders rather than obviating the trial altogether. Inability to communicate, for example, may arise from a stroke or coma, both of which may be alleviated with time or through special arrangements to facilitate communication. Memory problems at the time of the trial may constitute unfitness since they may impair the accused's proper appreciation of the proceedings. Yet, curiously, amnesia for the crime is insufficient, since it does not prevent a defence being made ${ }^{48}$ (although it may

\footnotetext{
44 N. Walker, Crime and Insanity in England, Volume 1: The Historical Perspective (Edinburgh: Edinburgh University Press, 1968).

45 D. Grubin, 'What Constitutes Fitness to Plead?' (1993) Crim LR 748, 750.

46 n 43 above, 47.

47 n 45 above, 751-752.

48 n 13 above; having no recollection, due to (hysterical) amnesia, does not make an accused eligible to be found unfit to plead. Also the presumption is that the defendant is sane / fit, so the burden falls on the defendant to prove otherwise. If raised by prosecution the standard to be satisfied is beyond reasonable
} 
impair the ability to put forward particular defences, for example, of provocation now 'loss of control' under the Coroners and Justice Act 2009).

Similarly, disorders of mood and emotional difficulties can affect one's ability to communicate and participate effectively, although they have not obviously fallen within the criteria for unfitness to plead.

\section{PROBLEMS TO BE ADDRESSED}

At this point it is instructive to return to the case of $W$ alls in order to examine why the views of the two psychiatrists as to his unfitness were rejected by the Court of Appeal.49 In formal terms, the psychiatrists were criticised for not making reference to the Pritchard criteria; arguably, the fault lies not with them but with those instructing them to prepare the reports, but without being privy to these it is hard to comment further. ${ }^{50}$ However, at the hearing both psychiatrists were subject to detailed questioning by counsel for the respondent, questioning from which it emerged one of the psychiatrists was not fully familiar with the details of Walls' police interview. That clinicians find themselves criticised and discomforted in a court setting should come as no surprise; perhaps what is more surprising is the court's rejection of the substance of the psychiatric findings. The courts are, of course, bound by Pritchard, but Pritchard has proved, with its focus on what constitutes 'a proper defence' (see below), malleable. The essence of the psychiatric testimony was that Walls' disability went beyond mere intellectual impairment to include disability and social handicap. His vulnerability to anxiety under stressful conditions and his impairments in relation to attention, concentration, and verbal skills would affect his capacity properly to instruct counsel, and to understand and follow evidence in court. He had significant cognitive defects and had difficulty in understanding causality and abstract concepts. Indeed, since he could not understand the charge or the details of the evidence, he would not be able to instruct lawyers effectively. Moreover, his anxiety might be misinterpreted by the jury as guilt. In short, the interaction between his low IQ and his other disabilities would put him at a substantial disadvantage.

The failure to engage with the details of Pritchard should not be a surprise. As long ago as 1995 Bowden had observed that, in court, psychiatrists tend to give a global view on unfitness accommodating their clinical judgement within the legal

\footnotetext{
doubt; if by the defence, the balance of probabilities. The SLC, n 27 above, s 5.59, recommended that the civil burden should apply to both prosecution and defence.

49 n 12 above.

50 Notably, A. Bickle and P. Stankard, 'Referrals for Expert Psychiatric Opinion on Dangerous Offenders: A Survey of Instructions Regarding Defendants Liable on Conviction to a Statutory Assessment of Dangerousness' (2008) 48(3) Medicine, Science and Law 211 observe that, in a study concerning the instructions given to psychiatrists under the Criminal Justice Act 2003, only six per cent referred the psychiatrists to the relevant statutory provisions on dangerousness.
} 
criteria. ${ }^{51}$ Professional discomfort with these procedures is also evidenced by James et al,52 who asserted that the current unclear position under Criminal Procedure (Insanity) Act 1964 tends to lead to 'pragmatic avoidance of the question of capacity by professionals concerned'.

However, it is curious that the Court of Appeal in Walls made reference to the Sevenoaks Youth Court case, ${ }^{53}$ where the Divisional Court had found the Youth Court to have a duty, under both common law and procedural rules, to appoint an intermediary in a case where such an appointment was necessary to ensure a young defendant received a fair trial and could participate effectively. The Court in Walls observed that no-one had raised the question of appointing such an intermediary. Yet they did so without bringing into question the fairness of Walls' trial, even though he had seemingly similar impairments to the defendant in the Sevenoaks case, namely intellectual impairment and learning disabilities which expert evidence said would impair his ability to concentrate, challenge evidence, and communicate effectively with his lawyer.

At one level these impairments, together with a reading age of nine, might be regarded as commonplace amongst those finding themselves in court - they are certainly not uncommon when the characteristics of those imprisoned are examined. And one can readily see why clinicians might conclude that such defendants cannot participate effectively in their own trials, even though they may understand the meaning of guilt in simple terms and recognise that they have been accused of doing something wrong. Injustice would seem writ large. Yet for lawyers working with the Pritchard criteria, and for lawyers who recognise the benefits of timely trials, with legal representation, justice may be seen as a more nuanced concept, and one that requires some final separation between those who should be tried and those who clearly cannot properly be exposed to judgment in its traditional form. Is this an irreconcilable clash between clinicians with a rosyeyed view of justice and lawyers with a blinkered view of the realities of plea and trial? Which profession bears the consequences of these judgments?

The Walls case crystallises the essence of the problem in unfitness to plead. Determining what competencies the defendant should have in order to be exposed to trial, and being able to assess them reliably, needs greater clarity if these decisions are to be made consistently. This is one of the justifications, perhaps the key justification, for the research being conducted by Blackwood et al under the terms of the Nuffield grant. ${ }^{54}$ But the case also exposes why the

\footnotetext{
51 P. Bowden 'Criminal Proceedings' in D. Chiswick and R. Cope (eds), Practical Forensic Psychiatry (London: Gaskell, 1995).

52 D. James, G. Duffield, R. Blizard, and L. Hamilton, 'Fitness to Plead. A Prospective Study of the Inter-Relationships between Expert Opinion, Legal Criteria and Specific Symptomatology' (2001) 31 Psychological Medicine 139, 148.

53 n 12 above.

${ }^{4}$ Nuffield Foundation research grant: 'Fitness to Plead: The Impact of Cognitive Abilities and Psychopathology' by Nigel Blackwood (Kings College London), Michael Watts (University College London), and Jill Peay (LSE).
} 
Pritchard criteria are in need of re-examination - a task on which the Law Commission have already embarked. Too narrow an approach to determining what constitutes unfitness will mean that some defendants, who are not able to participate effectively in their own trials, will necessarily risk being exposed to an unfair process and unjust punishment.

So we should be interested in what law means, what clinicians mean, what connects the two, what works, how it works, what the law ought to be, and which accused persons cannot be treated fairly if fairness is to be the core concept underlying the competency. Does the test currently include all it ought to include; is the threshold set too low so that those who are not fit are tried; or is the threshold acceptable, but its application problematic? And it has been argued that this depends not only on the nature of the accused and the test, but also the complexity of the case, requiring a more flexible approach by the judge. 55 Notably, and arguably in keeping with Grubin's proposals, it is now a matter for the judge to determine whether the defendant is fit to plead: the matter of the defendant's capacity is no longer left to a jury. Medical evidence will still be heard, but it is for the judge to interpret this, not a lay jury. ${ }^{56}$

\section{THE CURRENT POSITION}

The law on unfitness is under review and in flux; it also varies by jurisdiction, even within the UK (England and Wales, Scotland, and Northern Ireland are all different); Jersey and Guernsey, where there have been other developments, are British Crown dependencies and are not part of the UK legislative arrangements as such.

\section{ENGLAND AND WALES}

The essential position is set out in the 1836 case of Pritchard..$^{57}$

There are three points to be inquired into - first, whether the prisoner is mute of malice or not; secondly, whether he can plead to the indictment or not; thirdly, whether he is of sufficient intellect to comprehend the course of proceedings on the trial, so as to make a proper defence - to know that he might challenge any of you to whom he may object - and to comprehend the details of the evidence, which in a case of this nature must constitute a minute investigation. Upon this issue, therefore, if you think that there is no certain mode of communicating the details of the trial

55 n 45 above.

56 Domestic Violence Crime and Victims Act 2004, s 22(2), amending the Criminal Procedure (Insanity) Act 1964.

${ }^{57} \mathrm{n} 14$ above, at [304]. 
to the prisoner, so that he can clearly understand them, and be able properly to make his defence to the charge; you ought to find that he is not of sane mind. It is not enough, that he may have a general capacity of communicating on ordinary matters.

The gloss put on this in $\mathrm{R} v$ Podola 58 reiterates whether the accused is of sufficient intellect to comprehend, that is clearly to understand, the course of proceedings so as to be able properly to make his defence to the charge.

A somewhat more modern formulation can be seen in the case in of Friend: 59

$[\ldots]$ the accused will be able to comprehend the course of the proceedings so as to make a proper defence. Whether he can understand and reply rationally to the indictment is obviously a relevant factor, but [the jury] must also consider whether he would be able to exercise his right to challenge jurors, understand the details of the evidence as it is given, instruct his legal advisers and give evidence himself if he so desires.

Subsequently, the judge in $\mathrm{R} \vee M(J o h n)$ directed the jury that it was sufficient for the defence to persuade them on the balance of probabilities that any one of six things was beyond the appellant's capabilities in order to establish that the defendant was unfit to plead. And as the Court of Appeal noted approvingly in refusing an appeal against that ruling, those six things were as follows:

(1) understanding the charges; (2) deciding whether to plead guilty or not; (3) exercising his right to challenge jurors; (4) instructing solicitors and counsel; (5) following the course of the proceedings; (6) giving evidence in his own defence. ${ }^{60}$

Thus, making a proper defence, included in the formulation of the Pritchard criteria, seemingly embraces 'an ability to give evidence' (to understand questions and give intelligible replies). However, as the Court proceeded to explain, 'a loss of memory would not necessarily render an accused unfit to plead if he was able to do the various things described in Pritchard'.61 And nor, as in Robertson, ${ }^{62}$ would 'the mere fact that a defendant may not be capable of acting in his best interests during the trial'. It also noted that 'a jury should not be directed that the issue is whether he is able "properly" to instruct counsel, or to give "proper" evidence,,63 And finally the Court emphasised that 'merely because a defendant was highly

58 n 13 above.

${ }^{59} \mathrm{R} v$ Friend (1997) 2 Cr App R 231 at [240].

${ }^{60} \mathrm{M}$ (John) [2003] EWCA 3452 at [20].

61 ibid, at [29]-[30].

62 Robertson (1968) 52 Cr App R 690.

${ }^{63} M$ (Jobn), n 60 above, at [30]. 
abnormal did not mean that he was incapable of doing those things set out in Pritchard. ${ }^{64}$ Thus, the Court of Appeal observed, the 'authorities clearly establish the law on this topic in this jurisdiction [...] They do not set the test of fitness to plead at too low a level'. ${ }^{65}$

Sadly, mere recitation that something is clear does not make it so. The judgments in Pritchard/Podola are repeatedly approved, and yet these specifically make reference to the defendant's ability 'properly to make his defence'.66 Similarly, the addition of 'giving evidence' in the list of six above will necessarily entail fine judgments about whether it is in a defendant's best interests to give evidence or remain silent where his or her mental disabilities may lead the jury to come to erroneous conclusions, and particularly where they may now be entitled to draw adverse inferences from a defendant's silence.

Thus, it can be argued that there has been a shift in the direction of effective participation and away from a mere focus on the accused's cognitive capacities. Initially in the case of Pritchard it can be seen that there was no reference to instructing counsel. This shift can be seen in part in the case of Davies 1853, who was considered too mad to be capable of properly instructing counsel; in part with the 1836 Prisoners' Counsel Act, which introduced defence counsel in felony cases; and in part with the 1898 Criminal Evidence Act, which permitted accused persons to give evidence in their own defence. Clearly, with the widespread engagement of legal representation, the need for the accused themselves to enjoy the highest cognitive capacities is somewhat reduced, since counsel are present to translate and explain proceedings, ${ }^{67}$ but at the same time the need for the accused to be able to communicate effectively with their representative gains prominence. And it is not just a question of being able to give instructions, but also for those instructions to be understood by the representative and for any advice given to be understood in turn by the accused person.

\section{ATTORNEY GENERAL V O’DRISCOLL:68 THE JERSEY TEST}

Here, the court determined not to follow the Pritchard criteria, but rather to fashion its own future test. Thus, unfitness was to be based on an inability to participate effectively in proceedings:

An accused person is so insane as to be unfit to plead to the accusation, or be unable to understand the nature of the trial if, as a result of unsoundness of mind or inability to communicate, he or she lacks the capacity to participate effectively in the proceedings.

\footnotetext{
64 ibid.

65 ibid, at [31].

${ }^{66} \mathrm{nn} 13$ and 14 above.

${ }^{67}$ For example, in Stanford v UK (series A282-A). The ECtHR held there had been no breach of Article 6 where an accused with hearing problems had legal representation, and his representatives were aware of his hearing difficulties but chose not to bring them to the attention of the court.

68 Attorney General v O'Driscoll, n 30 above.
} 
In determining the issue regard shall be had to the ability of the accused:

a. To understand nature proceedings so as to instruct his lawyer and to make a proper defence;

b. To understand substance of evidence;

c. To give evidence on own behalf; and

d. To make rational decisions in relation to participation in the proceedings (including whether or not to plead guilty) which reflect true and informed choices on his part. ${ }^{69}$

The court retained the differential balance in the standard of proof where the burden fell respectively on the Crown or the accused. It recognised that the fact that unfitness was a judge- (or Jurat) based determination in Jersey meant that the court could rely on an experienced body of judges to arrive at reasonable conclusions following evidence of clinically recognised conditions, and not mere puzzlement by accused persons. But the desire of the court was evident to establish a test which protected the human rights and dignity of those afflicted by mental or physical incapacity and was consonant with the ECHR, developments in medical science, and appropriate to the social needs of their jurisdiction in the $21 \mathrm{st}$ century. ${ }^{70}$

\section{PROFESSOR MACKAY'S APPROACH}

Professor Mackay, who provided an expert opinion to the Jersey court in O'Driscoll, favoured a test that embodied two elements: whether the accused had the capacity to assist his lawyer, and whether he had decisional competence. ${ }^{71}$ The Jersey court's inclusion of the need for rational decisions that reflect true and informed choices on the accused's part derives from Professor Mackay's recommendations. ${ }^{72}$ This test is accordingly not only a test of functional competence, but also of decisional competence.

In the light of the Law Commission's Consultation Paper below, Mackay refined his proposals. ${ }^{73} \mathrm{He}$ agrees with the Commission that the Pritchard criteria are too narrow in focussing solely on cognitive criteria, and failing to take account of mental capacity and the ability to participate in a criminal trial (and some would also argue, failing to take proper heed of a defendant's impaired emotional state or even of mental disorders such as severe depression which can lead to feelings of pathological guilt). But he criticises the Commission for its proposal to replace

\footnotetext{
$69 \mathrm{ibid}$, at [29].

$70 \mathrm{ibid}$, at [27].

$71 \mathrm{ibid}$, at [25].

72 R. Mackay, 'On Being Insane in Jersey Part Three - The Case of Attorney-General v O'Driscoll' (2004) Crim LR 291.

73 R. Mackay, 'Unfitness to Plead - Some Observations on the Law Commission's Consultation Paper' (2011) Crim LR 433.
} 
this narrow test with a single test focussing on the accused's decision-making capacity with respect to the spectrum of trial decisions he or she might be called upon to make. Rather Mackay favours 'updating the Pritchard/cognitive criteria and supplementing them with a "decisional competence" limb'. ${ }^{74}$ Thus there would be a two-stage process: identifying those who were foundationally unfit (the bulk of those already identified by the Pritchard criteria) would precede (and obviate the need for, if an accused was found 'foundationally unfit') any assessment of impaired decision-making capacity and the need for special measures to support them.

Of course, given the numbers of prisoners with severe learning impairments, it is questionable whether the 'foundational' approach is working well at present, and it also raises the question of whether such convicted offenders ought not to have benefitted from special measures regardless of their decision-making abilities. Can these issues be so neatly divided up? Or is it suggested that the test of decisional competence will sweep up all those who ought properly to be within the unfit category? However, Mackay's recommendations will no doubt receive careful consideration, for he has been for many years the leading researcher and academic in this field in this country.

\section{THE SCOTTISH LAW COMMISSION}

It its 2004 Report the SLC recommended that the test for the plea of unfitness in bar of trial should be that:

$[\ldots]$ as a consequence of the accused's mental or physical condition at the time of trial he lacks the capacity to participate effectively in the proceedings against him. The test should include a non-exhaustive list of activities which would indicate such lack of capacity. ${ }^{75}$

A non-exhaustive list had been set out in the earlier Discussion Document; ${ }^{76}$ it included the ability to understand the nature of the charge, the need to tender a plea and its effects, to understand the purpose of a trial, to follow the course of a trial, to understand the substantial effect of evidence given against him, to communicate adequately with a legal representative, and to give adequate instructions to a legal representative.

Although having the disability was a prerequisite, it is the effects of the disability on the potential fairness of the trial and the accused's ability to participate which is critical.

To conclude this section on legal tests it is clear that a number of such potential tests were in existence before the Law Commission entered the field: Pritchard and its supplementary successors, which do not go far enough to embrace

\footnotetext{
74 ibid, 445.

75 n 27 above, s 4.19 .

76 n 28 above, 23.
} 
disorders beyond disorders of cognition to include emotional and mood disorders which may produce decisional incompetence; the Scottish approach, which is a detailed proposal with respect to the elements that make up effective participation; and the Jersey (and Mackay) approaches which go even further so as to embrace decisional incompetence, namely the failure to make capacious decisions which reflect true and informed choices by the accused (presumably the choices the accused would have made were he or she not afflicted by mental disability). For a test to be ECHR compliant the SLC argued that, even for those with limited capacity, compliance could be achieved if this were taken into account during proceedings, and the accused had adequate opportunities to discuss with counsel and have all relevant facts and arguments submitted on his behalf. In short, effective participation was the key, not necessarily full participation.

\section{THE LAW COMmission’s CONSUltation PAPER ON 'UNFitNess to PleAD’}

In October 2010 the Law Commission issued its consultation paper on Unfitness. ${ }^{77}$ The period for comments closed in January 2011: it may be some time before a final report is forthcoming. The Law Commission published in 2012 a further consultation paper on Insanity; ${ }^{78}$ this entails examination of the special verdict of not guilty by reason of insanity under the M'Naghten Rules. It is possible that any final recommendations on unfitness to plead and insanity will be published concurrently, necessarily incurring significant delay for the unfitness proposals. It is also notable that whilst CP 197 was warmly received in some quarters, its reception in others has been more mixed. ${ }^{79}$ In particular, caution has been expressed about the viability of a standardised psychiatric test (currently being researched by Blackwood, et al) ${ }^{80}$ which is regarded as central to the efficacy of the Commission's proposals and represents one of their 14 provisional proposals. ${ }^{81}$ The Commission argue that inconsistency in the application of the Pritchard criteria may reflect the inadequacy of those criteria, but:

$[\ldots]$ it is just as likely to be a reflection of the fact that there is no standard test for psychiatrists to use. We think that if there was a sound psychiatric test for assessing decision-making capacity in criminal proceedings, this would lead to consistency in assessments. ${ }^{82}$

\footnotetext{
$77 \mathrm{n} 4$ above.

${ }^{78}$ Law Commission, 'Consultation Paper on Insanity', forthcoming.

79 See, for example, discussion of the responses of the Bar Council and the Royal College of Psychiatrists in England below.

${ }^{80}$ n 54 above (research team: Blackwood, Watts, Peay, Brewer, and Appiah-Kusi).

$81 \mathrm{n} 4$ above, provisional proposal number seven, s 1.34 .

$82 \mathrm{ibid}, \mathrm{s} 5.14$.
} 
At this stage it is too early to judge whether a viable test will emerge from the research, ${ }^{83}$ and in the context of mixed responses to the Commission's proposals as a whole, only a brief synopsis of the Commission's relevant draft proposals will be offered here.

In essence the Commission are proposing a new legal test based on the decision-making capacity of the accused. Whilst their proposals are closely aligned with the requirements for identification of those lacking the capacity to make decisions under the Mental Capacity Act 2005, their test requires assessors to consider the accused's capacity with reference to the spectrum of trial decisions the accused might be required to make. Judges would need to take account both of the complexity of the particular proceedings and of the gravity of any likely outcome, but to do so in the context of the availability of special measures that might enable the accused to stand trial where reasonable adjustments can be made to trial procedures.

The Commission also propose changes to the section 4a hearing - the trial of the facts - so that the prosecution would be required to establish not only that the accused did the act or made the omission charged, but also that there are no grounds for an acquittal; this will take the prosecution into the territory of establishing mens rea. The difficulty this creates concerns the lacunae of those accused who have done the act, but for whom an acquittal results because of the accused's mental disorder at the time of the offence (ie, not an absence of mens rea, or even an insufficient mens rea, but the wrong kind of mens rea). Here it is proposed that a further hearing could take place which might then result in a compulsory therapeutic disposal (such a disposal being available had a positive finding been made in the first instance in the section 4 a hearing).

Royal College of Psychiatrists' response

A specific psychiatric test for capacity does not exist in civil law/the Mental Capacity Act 2005. We would argue that rather than leaving psychiatrists unequipped, this allows them the freedom to tailor their professionalism to each individual unique case. Mental disorders are diverse, individuals even more so and the psychiatric testing underpinning the legal capacity test will differ by condition and case. Introducing any defined psychiatric test along the lines suggested would appear to run the risk of creating a burden of rigid and perhaps unnecessary testing. ${ }^{84}$

This encapsulates well the clinical approach to unfitness, and underpins any likely resistance of psychiatrists to the introduction of a defined test, assuming the Blackwood, et al research is able to produce one tailored to the demands of

83 The test is still undergoing testing with a stratified 'normal' group, a psychotic sample, a learning disability sample, an autism spectrum sample, and a malingering sample. A final report will be prepared for Nuffield in 2012

${ }^{84}$ Royal College of Psychiatrists, 'Unfitness to Plead' (Consultation Response, 2 February 2011), 17. 
criminal trials. ${ }^{85}$ The College argues that such a test would be rigid and give a false impression of scientific validity, that it would be problematic to administer in prisons due to its reliance on technology, and that the problems should be resolved through better instructions from solicitors and reliance on a cohort of well-qualified experts in the field. Whilst better instructions are, of course, to be welcomed, this will not overcome the problem of ensuring a consistent approach to the assessment of unfitness. And it should be remembered that the Law Commission are not suggesting that such a test would replace a judicial determination of unfitness; it would just ensure that the psychiatric opinions that are presented in court address the defendant's relevant capacities. But it is evident that the psychiatric profession will require some persuasion before embracing any emergent test.

\section{The Bar Council's response86}

The Bar Council anticipates that if the Law Commission's proposals were adopted, there would be a significant increase in the number of findings of unfitness - an increase that will go considerably beyond even that anticipated by the Commission of an extra 500 cases a year. ${ }^{87}$ The Bar Council also have other anxieties, in particular with reference to applying a decision-making test, but these in turn portray a view of those seeking to employ unfitness as at best strategic and at worst manipulative. Thus, worries about a defendant having the capacity to plead guilty, but not to plead not guilty and face trial, produced the following comments:

Our tentative/provisional view is that such an outcome would be undesirable, and that a process that permitted such an outcome might be vulnerable to abuse by some defendants who choose to make a tactical decision to plead 'not guilty' whilst playing the 'medical card' in the hope that, for example, (a) a full trial, perhaps leading to conviction, might be avoided, or (b) the defendant can justify not giving evidence, or (c) the defendant can avoid adverse inference directions. 88

As with the Royal College of Psychiatrists, the Bar Council is sceptical as to the likely emergence of a reliable psychiatric tool, ${ }^{89}$ and is adamant that the ultimate determination of whether, or to what extent, the defendant lacks decision-making

\footnotetext{
$85 \mathrm{n} 54$ above. The anxieties the College expresses about the reliability and validity of such a test can only be addressed once a standardised instrument has been produced.

86 n 23 above.

87 The most recent figures suggest there are about 100 cases per year: see n 42 above.

88 n 23 above, 13.

89 ibid, 17.
} 
capacity ought to be a judgment for the court'. 90 In short, a tool can only inform the medical experts, and they can only give their opinions to the court.

It is thus notable that both the Royal College of Psychiatrists and the Bar Council have fiercely defended their traditional territories.

\section{CORE COMPETENCIES: WHAT MIGHT FAIRNESS MEAN TO THOSE LACKING THE NECESSARY CAPACITIES TO PLEAD OR STAND TRIAL?}

Fairness is not an easy concept as applied to the trial process: and there will be disparities between ideal trials and those conducted day-to-day in our trial courts. ${ }^{11}$ Achieving a completely level playing field is unrealistic, but avoiding one that has unjustifiable hazards for those not properly equipped to scale them might be.

Why might achieving fairness be more problematic for those with mental disabilities? First, there is the issue of objective and subjective fairness. What we are trying to achieve is a criminal justice system which is objectively fair in that it looks fair to outsiders, but also one which feels fair to the parties. ${ }^{92}$ Yet achieving 'fairness' is problematic where people hold irrational or paranoid beliefs or are inspired by irrational motives: their perception of what is fair may not be in accordance with that of others. And judging this from the perspective of an outsider is not necessarily straightforward. Thus, and drawing on two examples given by Wessely, et al,93 a man who wears a green tie to protect himself against a (believed) threat from the IRA may look objectively unremarkable to outsiders. However, a woman who reports her parents to the local police because she believes they are demonically possessed may have acted subjectively in a reasonable fashion, even though our contestation of the unreasonableness of the underlying belief would lead us to take notice of the behaviour. So man A may (inappropriately) slip past any unfitness threshold, whereas woman B, who has acted rationally, may get inappropriately (in her view) caught up. The 'effective

\footnotetext{
90 ibid, 21.

${ }^{91} \mathrm{n} 17$ above. Indeed, the higher courts are not always overly sympathetic to the needs of particular accused. Juries can now be instructed to draw adverse inferences where defendants do not give evidence; this can work against mentally disordered offenders, eg in Hassan Tabbakh [2009] EWCA Crim 464, it was argued that the defendant may not be able to do himself justice because he could not control himself in a witness box due to post-traumatic stress disorder. The court held that the jury would understand and allow for this. All the details were left to jury, and it was for them to decide whether or not to draw an adverse inference. Weighing the importance of giving evidence against the risk of harm to the defendant was accordingly a matter for the defendant and his legal advisors once the decision to hold a trial had been reached.

92 The need for subjective awareness, even amongst those whose levels of consciousness may be compromised, is supported by the recent case of $R$ v Clarke [2009] EWCA Crim 921, discussed in J. Rumbold and M Wasik, 'Diabetic Drivers, Hypoglycaemic Unawareness, and Automatism' (2011) Crim LR 863, 867.

93 S. Wessely, A. Buchanan, A. Reed, J. Cutting, P. Garety, and P. Taylor, 'Acting on Delusions I: Prevalence' (1993) 163 British Journal of Psychiatry 69.
} 
communication' which overlays this will thus hide a multitude of problems. It is also important to remember that people, both with and without disabilities, lie frequently about their motivations and beliefs on rational grounds, and these lies can, in turn, lead sometimes to unreasonable or irrational responses in others. So we need a system which is objectively fair and looks / feels as fair as is possible to others so that it can maintain public support; and yet be one that correctly identifies those who should not be being tried where such a process would objectively entail fundamental unfairness to an accused who cannot engage effectively with that process.

Second, there are the assumptions on which the criminal justice process is founded; for example, that defendants act strategically, act in their own best interests, and have the benefit of legal advice. How much of this is true?94 Indeed, acting in one's own best interests is explicitly discounted with reference to fitness, for example in Robertson where the appellant argued that the finding that he was under a disability should be quashed. The Court of Appeal agreed on the grounds that the jury may have been under the misapprehension that because Robertson's delusional thinking may have caused him to act otherwise than in his best interests, that he was under a disability. ${ }^{95}$ The appellant argued that despite his delusions he was capable of understanding the trial process and was, broadly, Pritchard compliant. Thus, he should not be deprived of his right to a fair trial just because he might not exercise his choices wisely. Thus it was the process of decision-making, not the outcome, that mattered.

Interestingly, much of the original hearing in Robertson concerned the Crown's argument about whether he was able properly to follow and apprehend the course of a criminal trial, etc. Perhaps this emphasis on properly derived from a close reading of the Pritchard criteria, as reiterated in Podola. ${ }^{96}$ But, the emphasis on the degree of understanding is interesting for two reasons: first, it is consonant with the medical approach which reflects degrees of disability rather than the legal approach which stresses a standard to be satisfied or rejected; and second, because it draws a distinction between the degree of understanding one might need, for example, to instruct counsel and the degree of capacity one might need to reach true and informed decisions unaffected by one's underlying disorder, the approach discussed above of decisional competence. However, the Court of Appeal in Robertson did not exploit such nuances and rather boldly rejected the notion that if one could not act in one's own best interests, one could nonetheless be fit to plead.

But, the position may be shifting, albeit fractionally. One recent case on the use of antisocial behaviour orders (ASBOs) is helpful, namely Cooke v DPP. ${ }^{97}$ This was an appeal against the imposition of an ASBO. There was a mental health

\footnotetext{
94 Or will remain true under proposed changes to legal aid?

95 n 62 above.

$96 \mathrm{n} 14$ above, at [304].

${ }^{97} \mathrm{R}$ (on the application of Jamie Cooke) v Director of Public Prosecutions [2008] EWHC 2703.
} 
report from a community psychiatric nurse $(\mathrm{CPN})$ which said that the appellant had mental health problems, but that he was not a danger. The Magistrates had doubted the evidential basis for that report since the CPN did not seem to be aware of appellant's previous convictions. More importantly, the Magistrates said that he had an understanding of the order made and did not consider it inevitable that he would breach any requirements imposed. On appeal the High Court concluded that the order should not be made if the impairment meant the appellant did not have the capacity to understand the order or comply with it. This is consonant with Duff's earlier argument about the importance of effective participation extending through to issues of censure. In so concluding the High Court cited Wookey v Wookey to the effect that injunctions should not be granted where it was impossible for those subject to the injunction to comply with them; this was because they would not have the desired deterrent effect or operate on his mind so as to regulate his conduct. ${ }^{98}$

The other line of reasoning in the judgment concerns the Magistrates' assertion that Cooke showed both consequential thinking and reasoned choices by selecting rational places to beg (alleyways and near cash-points) and living in the town centre, having rejected other accommodation. However, there is a problem with this in that it displays attributional thinking: do only the rational make objectively rational choices? Thus, the relationship between outcome and process is not straightforward. Sometimes an 'irrational' outcome may influence a judgment as to whether the prior process has been flawed: sometimes a seemingly rational outcome will cause one not to question the prior process. The example usually cited to illustrate this is that one's capacity to make decisions is much more likely to be questioned when one disagrees with one's doctor than when one does not.

On behalf of Cooke it was argued that the order was not necessary to protect the public since Cooke was incapable of complying with the order: consequently it was unjust and a wrong exercise of discretion to impose it if it was known that the order would be breached. The High Court agreed with this proposition, but concluded that Cooke was not incapable of complying. Where, for example, a personality disorder may result in making the subject liable to disobey the order, this would not constitute a sufficient reason for not making the order. Impulsiveness is not inevitability. What the courts seemed to require was a form of causative certainty. ${ }^{99}$ But is anti-social behaviour ever likely to be convincingly demonstrated to be caused by or consequent to a mental health disorder?

\footnotetext{
98 [1991] 2 FLR 319.

$99 \mathrm{n} 97$ above, at [18].
} 
WHAT CAPACITIES ARE NEEDED TO ENGAGE IN A COMMUNICATIVE TRIAL PROCESS?

Antony Duff has argued that the capacities required for fair trial include basic cognitive and intellectual capacities and a normative understanding of what it means to be charged and condemned. ${ }^{100}$ Therefore fit accused need both moral and emotional capacities, not just cognitive and intellectual ones. Moreover, just because one is able to plead, in the sense of communicating, does not mean one is fit to plead. Understanding what 'to plead' means is different from understanding that one might legitimately plead differently. For example, fairness to those who are pathologically depressed, and who can see no point in contesting matters since they believe they deserve punishment, may require the 'time-out' from full trial that an unfitness process can provide, so that their responsibility for the crime can properly be judged at a time when they can engage (that is, they may be properly liable for a verdict of manslaughter on grounds of diminished responsibility, whereas their inclination, were a plea to be tendered at the earliest opportunity, may be to plead guilty to murder).

Aside from those whose psychotic states may lead them to believe they have a viable defence (when they do not), or have no viable defence (when they may have), or are neglecting, for example, the advantages that may accrue from a guilty plea, and those whose affective states may cause them inappropriately to welcome punishment, perhaps the main contenders for unfitness findings are to be found, at least in practice, amongst the intellectually impaired. The intellectually impaired will, by definition, be likely to find participating in the trial process more challenging than others, although it should be noted that 40 per cent of defendants with no diagnoses at all were found to be impaired on one or more aspects of legal ability as measured by the 'Fitness Interview Test. ${ }^{101}$

Trials are challenging events. Getting effective participation, and hence achieving fairness, will require for many defendants significant assistance in court, and arguably assistance going beyond that offered by legal representatives. ${ }^{102}$ Similarly, the position of young defendants (some would prefer the term 'children' were the legal age of criminal responsibility higher than it currently is at 10) poses further problems. The ECtHR has already found that, even with the special arrangements in place, 10-year-old defendants were denied a fair trial in light of their youth and lack of understanding of legal process: they were regarded as highly unlikely to have been able to follow the proceedings properly or to pass information to their lawyers, which constituted a breach of Article 6.103

\footnotetext{
100 n 17 above.

101 J. Viljoen, R. Roesch, and P. Zapf, 'An Examination of the Relationship between Competency to Stand Trial, Competency to Waive Interrogation Rights and Psychopathology' (2002) 26 Law and Human Behavior 481.

102 n 31 above.

103 n 37 above.
} 
As has already been noted, unfitness based on mental impairment is a main diagnosis in 21 per cent of cases. ${ }^{104}$ There is, of course, an argument that those whose intellectual impairments lead them into conflict with the law ought perhaps not to find themselves subject to the criminal law at all. Andrew Ashworth has cogently argued that the Rule of Law requires that those who are ignorant of the strictures of the criminal law ought perhaps not to be subject to it, or not subject to its full force. ${ }^{105}$ There is, of course, a difference between 'don't know' and 'can't know', but the thesis is nonetheless compelling, albeit controversial. Paradoxically, lawyers have been all too fond of arguing both that ignorance of the law is no defence and yet extol the virtues of the Rule of Law. Even if such allowances were not to be made, force remains in the argument that it is unfair to punish those who are unaware of their own wrong-doing. Unawareness can also be both factual, which is much less likely, or legal. Moreover, the source of this unawareness can vary. But where it stems from intellectual impairment, it may be right to argue that the courts should do more than look, as they currently do in unfitness findings, for an underlying clinical condition (the medical cloak of respectability) which underpins the intellectual impairment. Rather it should be accepted that those without the intellectual wherewithal to understand a trial process should simply not be subject to its full rigours without some significant accommodations being made. And if these are not possible, then a finding of unfitness may be the fairest outcome.

Yet at present, as Mackay has frequently observed, defendants will be found fit with only a rudimentary understanding of trial process, and those with mood and delusional symptoms may be excluded altogether from the protections that an unfitness finding offers. ${ }^{106}$ The narrowness of Pritchard and its rigorous application by the courts have ensured this. In some cases the courts have been open about this, as for example in Walls above; in others the support is tacit: but the implicit view is that it may be better to be tried 'unfairly' than not tried at all. The disposal options that follow on from a finding of unfitness (together with a finding that the accused did the act or made the omission charged in a trial of the facts) are just not sufficiently enticing.

There is also an argument about asymmetry. The capacities required to plead guilty may not necessarily mirror those required to plead not guilty (as the Bar Council observed above). ${ }^{107}$ The time frame for the former is more limited, albeit that punishment may follow more quickly. Arguments here may turn on the severity of the offence and the nature of the punishment which may follow.

\footnotetext{
$104 \mathrm{n} 41$ above; and on the position in Scotland, see E. Brewster, E. Willcox, and F. Haut, 'Assessing Fitness to Plead in Scotland's Learning Disabled' (2008) 19(4) The Journal of Forensic Psychiatry \& Psychology 597. This study also notes the unfamiliarity of many psychiatrists working in the field of learning disability with the relevant case law in Scotland.

105 A. Ashworth 'Ignorance of the Criminal Law, and Duties to Avoid It' (Chorley Lecture, LSE, June 2010).

106 For an assessment of the usefulness of one of the American tests, see R. Mackay, 'AAPL Practice Guideline for the Forensic Evaluation of Competence to Stand Trial: An English Legal Perspective' (2007) 35(4) Journal of the American Academy of Psychiatry and the Law 501.

107 n 86 above.
} 
Where deprivation of liberty is at stake, more capacity may be required than where a guilty plea may be followed by a non-custodial punishment, particularly if the latter has an evidently therapeutic element. But to plead not guilty will require the accused to forgo any sentence discount and will entail a sustained involvement in the trial process, with all of its complexities.

\section{WHAT CLINICALLY MIGHT BE RELEVANT?}

Following their study James, et al ${ }^{108}$ concluded that the two most relevant legal criteria in making clinical decisions about unfitness were: could the accused follow legal proceedings to trial, and could they give adequate instructions to a solicitor including, tangentially, understanding the details of evidence. Again, both of these are consonant with an approach based on fairness and the need for the accused to be engaged in a communicative process.

Unfitness was significantly associated with positive psychotic symptomatology, and especially conceptual disorganisation and delusional thinking / unusual thought content. Delusions may need to bear on relevant issues to make the accused unfit, whereas arguably conceptual disorganisation will always impair fitness. Symptoms of anxiety, depression, and withdrawal were less obviously relevant. Thus, symptoms affecting comprehension and communication were the most important, at least insofar as they correlated with the final subjective judgments of unfitness. ${ }^{109}$

Indeed, as Rogers, et al observe, citing the 12 potentially relevant areas of psychological assessment,

[...] comprehension; reasoning ability; consistency; memory; concentration and attention; suggestibility; inappropriateness; impulsivity; insight; affect; passivity; and the dangers of 'faking bad'. It is immediately clear that the existing Pritchard criteria are by no means comprehensive. It seems likely that many defendants both with and without a mental disorder will perform poorly in a number of these areas without concerns ever being raised about their fitness. ${ }^{110}$

Indeed, in a parallel publication by the same team of clinicians looking at barristers' views about the fitness provisions, the authors observe that 'significant

\footnotetext{
108 n 52 above.

109 T. Rogers, N. Blackwood, F. Farnham, G. Pickup, and M. Watts, 'Fitness to Plead and Competence to Stand Trial: A Systematic Review of the Construct and Its Application' (2008) Journal of Forensic Psychiatry and Psychology 576, 592.

110 ibid, 581 .
} 
numbers of the mentally ill continue to undergo trial'; 111 and the implication is that these trials are likely to be unfair.

\section{CORE COMPETENCIES: CONCLUSIONS}

If fairness is the preferred prevailing legal concept in unfitness to plead, which core competencies would one need to make fairness a reality? Are James, et al correct to identify as the two core competencies: following legal proceedings to trial, and giving adequate instructions to a solicitor?112 And can these core competencies, if absent, be fully supplemented by an advisor / friend in the courtroom, were such an individual to be provided for vulnerable defendants, as recommended by the Bradley Report?113 After all, legal fairness means both trying those who are fit to be tried, or who can be supported to be fit, and diverting into the alternative 'unfitness' arrangements only those of uncertain culpability (not necessarily 'at fault' due to absence of agency or freedom to choose, that is people to whom we would attribute moral responsibility) but proven causal factual liability, albeit not legal liability.

Ideally, a combination of the Commission's decision-making test geared to the demands of a criminal trial, supplemented by some support provisions at trial which enable those who can be enabled to participate in a criminal trial (or to tender a guilty plea), would go a considerable way to solving the conflicting demands made by 'fair trials'. However, since identification of those who may face difficulties at trial is critical, the development of a sensitive screening tool to assess capacity for trial is undoubtedly a key prerequisite. Setting the threshold for what thereafter constitutes the division between those who can be fairly tried, and those who should not be exposed to the likelihood of an unfair process would be a matter for the courts, not clinicians, to determine, in the light of their knowledge of the problems and possibilities that particular combinations of charges, factual situations, and accused persons face. Timely, fair trials are, however, the goal.

\footnotetext{
111 T. Rogers, N. Blackwood, F. Farnham, G. Pickup, and M. Watts, 'Reformulating Fitness to Plead: A Qualitative Study' (2009) 20 Journal of Forensic Psychiatry and Psychology 815, 817.

112 n 31 above.

113 n 39 above, for a critical appraisal.
} 


\title{
APPENDIX ON CORE COMPETENCIES
}

Determining what competencies are core requires some understanding of the range and effects of the most common conditions that can afflict defendants' decision-making abilities with respect to trial procedures. Our appreciation of these has expanded since Pritchard, but would include:

\author{
Schizophrenia \\ Delusional Disorders \\ Psychotic Depression and Depressive Disorders \\ Bi-Polar Disorder \\ Obsessive Compulsive Disorders \\ Autism / Asperger's Syndrome \\ Organic Brain Disorders - Alzheimer's, Creutzfeldt-Jakob disease, \\ Deliriums, Dementias \\ Learning Disability \\ Personality Disorders, including Psychopathy
}

These variously impair defendants' autonomy to their disadvantage at trial. The medication used to treat these conditions can also have a deleterious effect on a person's ability to participate in their defence. If left untreated, these conditions can subvert an accused's sense of reality, leaving them with a distorted sense of present and past events that supplants the objective existing reality, or, in a state of acute confusion. They may be incapable of concentrating, organising, or retaining information, and in cases of dementia are left with a jumbled mass of confused thoughts and short-term memory problems. All of this impairs their judgement and ability to make informed choices. There is (to varying degrees) an inability to understand the trial process, their role within it and their rights - and any corresponding sanctions. Obtaining their informed consent is fraught with difficulty and may prove impossible. The Pritchard criteria do not recognise these subtleties.

Core competencies can be broken down in a number of ways. One approach is to divide these into those required to participate and yet not give evidence, and those required specifically where a defendant enters the witness box and is subject to cross-examination. For both, the ability to make decisions is implicit.

1. Ability adequately to understand and participate in Court proceedings

This will embody the ability to understand the nature of the proceedings so as to instruct his lawyer and to make a proper defence, and thus will comprise: 
a. An adequate understanding / orientation of the trial process - order of proceedings, roles and responsibilities, purpose and effect, consequences;

b. Adequate organisational skills to assist in the preparation and presentation of one's defence - provision of instructions / ability to respond to evidential developments pre / during trial (ie the ability to understand the evidence and the ramifications of the evidence);

c. Adequate concentration, memory, and linguistic skills to follow what is said during a trial and respond to it;

d. An adequate ability to recognise individual responsibility / autonomy in decision making, the prerequisite for informed consent, and the ability to make such decisions;

e. An ability to acknowledge the formal impartiality of proceedings and of the professional parties, and not to be unduly affected by paranoid beliefs about the various parties;

f. An adequate orientation in time and place to be able to understand the consequences that will stem from participating in a plea or trial at this point; and

g. A reasonable ability to make decisions and sustain those decisions.

Subsumed in this competency is the ability of the accused to understand the substance of the evidence, and to make decisions in relation to participation in the proceedings (including whether or not to plead guilty), which reflect true and informed choices on his / her part. ${ }^{114}$

\section{The ability to understand and give evidence}

This issue concerns whether an accused is able or (more relevantly) unable to give evidence, or if there is doubt as to a person's soundness of mind, which would vitiate their capacity to give evidence; these should turn on medical evidence of incapacity.

114 n 29 above. 
It will comprise:

a. An ability to give evidence without undue risk to health; ${ }^{115}$

b. An inability to give evidence even given reasonable accommodations to the process (eg appointing an intermediary - for physical disabilities, a parallel example in back pain might be to allow someone to sit);

c. An ability to give evidence without being so unreasonably affected by anxiety, stemming not from the usual demands of trial but from an underlying condition, as to prejudice a jury's assessment of guilt;

d. An ability to understand questions and give intelligible replies; and

e. An ability to appreciate the distinction between what is true, what may be true, what are false beliefs, and what are manifest lies.

115 See T. Ward, 'Hearsay, Psychiatric Evidence and the Interests of Justice' (2009) Crim LR 415. Ward notes two examples from Friend (no 1) 1997 1WLR 1433 CA (Crim Div) at [1442], where the Court of Appeal acknowledged that the sorts of conditions that might satisfy s 35(1)(b) of the Criminal Justice and Public Order Act 1994 would be epilepsy and latent schizophrenia where the experience of giving evidence might trigger an attack or florid state. In Friend (no 2) [2004] EWCA Crim 2661, the CA added Attention Deficit Hyperactivity Disorder where a defendant might blurt out something or give conflicting evidence. Thus, a defendant in such circumstances might be fit to plead but not to give evidence under $\mathrm{s}$ 35 and have adverse inferences drawn. Ward, 419, also notes the CA's approval in $M$ (Jobn), n 60 above, of a direction adding an ability to give evidence to the Pritchard criteria. 